\title{
COVID-19 Endangers the Health of Society by Disrupting Social Participation, Home Integrations, and Productive Activities.
}

\section{Elyas Monfared}

University of Social Welfare and Rehabilitation Science

\section{Mohsen Vahedi}

University of Social Welfare and Rehabilitation Science

Hojjat Allah Haghgoo ( $\square$ haghgooh@gmail.com )

University of Social Welfare and Rehabilitation Science https://orcid.org/0000-0001-6136-2417

\section{Research article}

Keywords: Home integration, Social integration, productive activity, community integration questionnaire, COVID-19, activities of daily living

Posted Date: February 4th, 2021

DOI: https://doi.org/10.21203/rs.3.rs-167122/v1

License: (c) (i) This work is licensed under a Creative Commons Attribution 4.0 International License. Read Full License 


\section{Abstract}

Objective

Proper social participation and involvement in the daily activities of life increases the feeling of attachment, and increases a person's sense of worth, belonging, and dependence on society. Lack of social communication leads to anxiety, loneliness, depression, panic, mental. While COVID-19 has become a pandemic, public health measures to cut off human-to-human transmission may include quarantine and social isolation. Due to social distancing and quarantine practices, people's participation in many areas of social life and daily activities has been disrupted. The purpose of this study is to provide insight into the effects of the Covid 19 epidemic on integration into home activities, integration into the community and integration into productive activities, and overall determination of social participation during this epidemic.

Methods

In June 2020, the Social Integration Questionnaire (CIQ), which measures integration at home, integration in the community, and integration into purposeful and productive activities, was transcribed with the required demographic information in a web-based format. A total of 461 people (mean age $36.86 \pm 5.8$ years) completed the social integration questionnaire in a cross-sectional study. The effects of Covid-19 on social interaction were then calculated by analyzing CIQ scores before and after the outbreak of COVID-19 and the data were analyzed using SPSS software version 22.

Results

Comparing the participants score in the Community Integration Questionnaire before and after the COVID19 pandemic showed that COVID-19 reduced home integration (from $4.6909 \pm 2.84$ to $3.5938 \pm 2.80$, $t=$ $11.151 p<0.000$ ), social integration (from 8.6529 \pm 1.98 to $6.1150 \pm 2.10, t=25.440, p<0.000$ ), integration into productive and purposeful activities (from $5.3145 \pm 1.70$ to $3.5098 \pm 2.02, t=23.226, p<0.000$ ) and total CIQ test score (from 18.6584 \pm 4.02 to $13.2185 \pm 4.56, t=29.022, p<0.000$ ). These findings show how all three CIQ domains and their total scores decreased significantly after the outbreak of COVID-19.

Conclusion

After the COVID-19 epidemic, people's social life is severely disrupted. The direct and indirect psychological and social effects of COVID- 19 are widespread and can affect mental health.

Trial Registration: This study was registered and approved by the Ethic Committee of the University of Social Welfare and Rehabilitation Sciences, Tehran, Iran (IR.USWR.REC.1399.228).

\section{Introduction}


Social participation and involvement in the activities of daily living require the maintenance of a variety of social relationships, relationships with others, and involvement in various social and daily activities of life (1). These activities include meeting and interacting with family and friends (2), participating in religious activities (3), participating in a job or social roles (for example volunteering) (4), participating in cultural, sports, and academic activities (5) or attending various meetings (planning recreational or business meetings) and work-related to home and self-care (6). Proper social participation and involvement in the daily activities of life increase the feeling of attachment, provides a sense of consistent and cohesive identity, and increases a person's sense of worth, belonging, and dependence on society. Man is a social being and his health and growth depends on his social relations, and we as human beings are a social being who owes our life and civilization to social interactions (4). In this regard, Prilleltensky et al. (7) reported that integration into the community and participation in social activities actively increase well-being, psychological status, and a sense of belonging. Similarly, Smetana et al. (8) showed that social participation increases adolescents' sense of self-confidence and self-control and community involvement enhances the psychological health of every human being.

In defining the term "social health", increasing social participation is one of the important goals of health professionals (9). The World Health Organization (WHO) recommends that special attention be paid to social participation, especially for older people because they spend less time in socially structured environments (10). In addition, social participation and involvement in the activities of daily living have a positive and important role in personal well-being (e.g. life satisfaction) (11) and social well-being (4). On the other hand, participating in personal leisure activities (which is a form of social participation) is of great importance for physical and mental health and improving the quality of life (12). Lack of social communication leads to anxiety, loneliness, depression, panic, mental disorders, and many other issues in people's lives and affects society in general (13).

A new COVID-19virus, called COVID-19, was discovered in December 2019 in Hubei, China. In just one year, COVID-19 reportedly infected about 100 million people (as of January 25,2021 ) worldwide, of whom about 2.14 million died (14). It seems that the growth potential of this virus in the world has become a pervasive (15)disease and a serious threat to public health. The WHO has identified COVID-19 as a "highlevel" threat (16). At present, treatment strategies to combat the virus are fully supportive, and prevention is the best way to break the transmission chain in society. Social distancing and quarantine measures in different countries have led to a gradual decrease in the number of patients in recent days (17).

While COVID-19 has become a pandemic, public health measures to cut off human-to-human transmission may include quarantine and social isolation. These measures restrict mobility at the community level or separate individuals. Quarantine or social isolation between individuals is a restriction on the activities or separation of people who are not sick but may be exposed to infectious agents or disease. Due to social distancing and quarantine practices in many countries, people's participation in many areas of social life and daily activities have been disrupted (18). While quarantine measures have already been used to combat infectious diseases (such as cholera, SARS, and Ebola) $(15,19,20)$, this level of quarantine on a world-wide scale is unprecedented throughout history (21). 
Although social isolation and quarantine measures are an effective solution to slow the spread of infectious diseases, at home they can also have negative effects on mental health and several behaviors in life, including social participation and life satisfaction. In fact, recent studies have shown that quarantine measures by COVID-19 increases the number of inactive individuals $(22,23)$. These people experience unhealthy dietary behaviors (22), psychological and emotional disorders, as well as lower quality of sleep as a result of house arrest $(22,24)$. In the context of social participation and life satisfaction, it has been suggested that COVID-19 and related quarantine may be associated with feelings of loneliness, sadness, and loss of life satisfaction (25-27). Social distancing policies affect the perspective of our social life and bring about changes in social communication and daily life practices. Various studies have shown the effect of this disease on people's lives and the severe consequences of this disease on individual and social life, including social anxiety, panic, economic recession, and psychological stress resulting from its prevalence $(13,28-31)$.

Recent research has also highlighted the urgent need for research to help the public better understand the psychological consequences of COVID-19 (32). To help describe the psychosocial effects of the COVID19 crisis, our research team conducted an anonymous survey in Iran to assess the results of quarantine and social distancing on psychological status and various lifestyle behaviors during the COVID-19 outbreak. The purpose of this study is to provide an insight into the effects of the COVID-19 epidemic on integration into home activities, integration into the community and integration into productive activities, and overall determination of social participation during this epidemic. The findings of this study help us to find a solution to overcome the social isolation caused by the disease and to adjust our social system with proper planning, regardless of the fears and threats of the disease. The ultimate goal is to highlight the importance of setting up programs to support people through this crisis.

\section{Materials And Methods Of Review}

This study was approved by the Ethic Committee of the University of Social Welfare and Rehabilitation Sciences, Tehran, Iran (IR.USWR.REC.1399.228).

A total of 461 participants (mean age 36.8685 .8 years) participated in a cross-sectional study by filling out the Community Integration Questionnaire (CIQ) online., the study was conducted through an online survey in May and June 2020 in Iran in which respondents were invited to complete the questionnaire through the World Wide Web, which was available for 2 months to be completed

The study process and sampling method in this study was as follows: CIQ with the required demographic information (including gender, marital status, level of education, employment status, life status, and disability) were transcribed in a web-based format. A global source link (URL) in "Porsline.ir" was sent to the participants via WhatsApp, email, and messenger. They were invited to complete the survey. Participants and the target population included a long list of students, patients, and people with and without disabilities, their families and relatives, and others who could use smartphones, computers, tablets, and laptops. 
The inclusion criteria for entering the research include: (1) having a tablet, computer or mobile phone with the Internet that has the ability to connect to the designed Internet site and complete the questionnaire, and (2) filling out the questionnaire. The completed questionnaires with incorrect information were also excluded from the research process; furthermore, the questionnaires with the same IPs were also excluded from the review process.

\section{2-1 CIQ Scoring}

There are two versions of CIQ, one for patients and one for family members. We used the family member's version. This questionnaire is (especially) sensitive to the scale of productive activities, which can be used to identify barriers to productive activities. CIQ includes three sub-categories: 1-Home integration with 5 items with 10 points (including shopping items, food preparation, daily chores, childcare, and social program coordination), 2-Community integration with 6 items -12 points-including Personal finances, number of times to leave the house to do shopping, leisure activities, meeting friends, doing leisure activities with family or friends and having a close friend, 3-Integration in purposeful and productive activities with 4 items -7 points- including the number of getting out of the house per week, work status, educational status, participation in volunteer activities. The full CIQ score is 29.12 items out of 15 items of $\mathrm{CIQ}$ questionnaire are scored between 0-2. A higher score indicates more independence and better interaction. The validity and reliability of this questionnaire was proved in 1994 for adults (33, 34). Also the validity and reliability of the Persian version of this questionnaire were proved in 2013 (35). The questionnaire items were also adjusted to show the individual's social interaction before and after the COVID epidemic. Therefore, two sets of data have been collected: before the outbreak of COVID-19 and after the outbreak of COVID-19.

\section{2-2 Scoring and analysis data}

Items related to interaction at home and in the community are rated between $0-2$. Item 4 "Who usually takes care of the children at home?" has 4 options, which include "myself alone, me and another person, another person alone and this question is not suitable for me". 3 and 5 are calculated using average of items 1, 2, 3, and 5. To rate items 13 through 15, we used the instructions provided by Dr. Barry Wheeler (WWW.rehabmeasures.Org). Demographic information including age, sex, marital status, occupation, level of education, and disability were also recorded. Data were analyzed using SPSS software version 22. Differences between test scores before and after COVID-19 were analyzed using paired t-test.

\section{Results}

A total of 461 subjects answered the questionnaire and their demographics are presented in table 1.

\section{Table 1: Demographics for the total Sample}




\begin{tabular}{|c|c|c|c|}
\hline \multicolumn{4}{|l|}{ Gender } \\
\hline Male & & $\mathrm{N}=177$ & $(38.4 \%)$ \\
\hline Female & & $\mathrm{N}=283$ & $(61.4 \%)$ \\
\hline Undefined & & $N=1$ & $(0.2 \%)$ \\
\hline \multicolumn{4}{|l|}{ Marital Status } \\
\hline Single & & $\mathrm{N}=146$ & $(31.7 \%)$ \\
\hline Married & Divorced/Separated & $\mathrm{N}=305$ & $(66.3 \%)$ \\
\hline Education & & $\mathrm{N}=10$ & $(1.9 \%)$ \\
\hline \multicolumn{4}{|l|}{ Bellow diploma } \\
\hline Diploma & & $\mathrm{N}=19$ & $(4.1 \%)$ \\
\hline Bachelor's Degree & & $N=82$ & $(17.8 \%)$ \\
\hline Master Degree or higher & & $N=190$ & $(41.2 \%)$ \\
\hline Current Employment & & $N=170$ & $(36.9 \%)$ \\
\hline \multicolumn{4}{|l|}{ Unemployed } \\
\hline Competitive & & $N=62$ & $(13.5 \%)$ \\
\hline Labor & & $N=102$ & $(22.1 \%)$ \\
\hline Staff & & $\mathrm{N}=18$ & $(3.8 \%)$ \\
\hline Retired & & $N=106$ & $(23.1 \%)$ \\
\hline Volunteer & & $N=27$ & $(5.8 \%)$ \\
\hline University Student & & $N=9$ & $(1.9 \%)$ \\
\hline School student & & $N=80$ & $(17.3 \% t)$ \\
\hline Otherwise & & $N=4$ & $(1.0 \%)$ \\
\hline Living Status & & $N=53$ & $(11.5 \%)$ \\
\hline \multicolumn{4}{|l|}{ Alone } \\
\hline With Spouse & & $N=53$ & $(11.5 \%)$ \\
\hline With spouse and children & & $N=84$ & $(18.3 \%)$ \\
\hline With Parents & & $\mathrm{N}=222$ & $(48.1 \%)$ \\
\hline Disability & & $N=102$ & $(22.1 \%)$ \\
\hline \multicolumn{4}{|l|}{ Un-Disabled } \\
\hline Disabled & & $\mathrm{N}=447$ & $(97 \%)$ \\
\hline
\end{tabular}


The participant's scores in CIQ are summarized in table 2.

Table 2. Comparing the participants score in the Community Integration Questionnaire before and after the COVID-19 pandemic

\begin{tabular}{|c|c|c|c|c|}
\hline Sample Size=461 & Mean $\pm S D$ & $\mathrm{t}$ & $d f$ & Sig. (2-tailed) \\
\hline Home Integration Total Pre-Test & $4.6909 \pm 2.84$ & \multirow[t]{2}{*}{11.151} & \multirow[t]{2}{*}{460} & \multirow[t]{2}{*}{.000} \\
\hline Home Integration Total Post-Test & $3.5938 \pm 2.80$ & & & \\
\hline Social Integration Total Pre-Test & $8.6529 \pm 1.98$ & \multirow[t]{2}{*}{25.440} & \multirow[t]{2}{*}{460} & \multirow[t]{2}{*}{.000} \\
\hline Social Integration Total Post-Test & $6.1150 \pm 2.10$ & & & \\
\hline Integration Into Product Activities Pre-Test & $5.3145 \pm 1.70$ & \multirow[t]{2}{*}{23.226} & \multirow[t]{2}{*}{460} & \multirow[t]{2}{*}{.000} \\
\hline Integration Into Product Activities Post-Test & $3.5098 \pm 2.02$ & & & \\
\hline Total CIQ Pre-Test & $18.6584 \pm 4.02$ & \multirow[t]{2}{*}{28.022} & \multirow[t]{2}{*}{460} & \multirow[t]{2}{*}{.000} \\
\hline Total CIQ Post-Test & $13.2185 \pm 4.56$ & & & \\
\hline
\end{tabular}

The table illustrates how all three domains of the CIQ and its total score decreased significantly after COVID-19. The trend of decrease in three domains of CIQ is presented in diagrams 1-4.

According to the recent results, about 25 percent of respondents said that before the COVID-19 outbreak, someone else had bought food or other necessities at home, which increased to 37 percent after the COVID-19 outbreak. Nevertheless, despite the relative increase in respondents' shopping alone (from $24 \%$ to $28 \%$ ), their participation in shopping with someone else decreased from $49 \%$ to $32 \%$.

Forty-one percent of respondents reported that before the COVID-19 someone else had prepared food for them at home, which has risen to $38 \%$ since the COVID-19 outbreak. While participation in home cooking has increased (from $21 \%$ to $24 \%$ ), the percentage of those who cook at home alone has decreased slightly (from $36 \%$ to $35 \%$ ).

About $27 \%$ of respondents said that someone else did the housework before COVID-19,, which dropped to $25 \%$ after the outbreak of COVID-19. While the rate of personal participation in daily household chores was approximately equal before and after the COVID-19 outbreak (40\%), people doing daily household chores alone increased (from $31 \%$ to $32 \%$ ).

The percentage of those who cared for children at home was $14 \%$ before the COVID-19 outbreak and decreased to $8 \%$ after the outbreak of COVID-19. The participation rate in childcare increased from $18 \%$ to 
$24 \%$ and the percentage of those alone caring for children increased from $16 \%$ to $18 \%$. Half of the study participants $(48 \%)$ had no children under 17 years at home.

About 10 percent of respondents stated that they did not participate in any social get together programs with friends and family before the COVID-19 outbreak, which increased to 61 percent after the outbreak of COVID-19. In addition, the number of people who coordinated periodic social programs decreased from $15 \%$ to $7 \%$, and the percentage of respondents who coordinated these programs with others decreased from $56 \%$ to $20 \%$. It should also be noted that the percentage of people who coordinated these programs alone has decreased from $15 \%$ to $9 \%$. This indicates a sharp decline in social communication and planning of such communities.

Before COVID-19, the number of people whose personal finances were managed by someone else was $16 \%$, which increased to $29 \%$ after the outbreak of COVID-19. Also, the level of participation of individuals in performing their personal affairs have decreased from $56 \%$ to $52 \%$, and participation with another person in managing personal finances decreased from $25 \%$ to $17 \%$.

Before COVID-19, only $2 \%$ of respondents did not leave home for shopping in a month, which has increased to $20 \%$ since the COVID-19 outbreak. While the percentage of people who went out shopping four times a month increased from $35 \%$ to $62 \%$, the percentage of people who went out of home five or more times a month decreased (from $61 \%$ to $15 \%$ ).

Ninety-two percent of respondents reported that they went out for recreational activities at least once a month, before COVID-19, which dropped to $18 \%$. Also, the number of people getting out of home four times a month to participate in leisure activities decreased from $48 \%$ (before) to $12 \%$ (after the COVID19). In addition, the number of people who went out 5 or more times a month dropped from $41 \%$ to $3 \%$. The level of participation in recreational activities has decreased significantly.

Prior to the COVID-19 outbreak, only $4 \%$ of respondents did not leave home for a month to visit friends and family, which increased to $41 \%$ after the COVID-19 outbreak. Despite this, the number of people get out of home four times a month to visit friends and family decreased slightly (from $50 \%$ before the COVID-19 to $49 \%$ after the COVID-19), the number of people leaving home 5 or more times a month for meeting friends and family has dropped from $43 \%$ to $7 \%$.

Seven percent of respondents were involved in recreational activities alone before the COVID-19 outbreak, which increased to 27 percent after the COVID-19 outbreak. Although participation in such activities with family increased from $32 \%$ before the COVID-19 outbreak to $70 \%$ after the COVID-19 outbreak, participation in these activities with friends decreased from $57 \%$ to approximately $0 \%$.

There was no difference between having a close friend before and after COVID-19. Prior to COVID-19 only $3 \%$ of respondents reported leaving home rarely / never (or less than once a week), which increased to $43 \%$ after COVID-19. Also, the number of people leaving home every day to engage in various activities decreased from $76 \%$ (before the COVID-19 outbreak) to $22 \%$ after it. 
People who did not participate in school/work and productive activities were $6 \%$ before the COVID-19 outbreak, which then increased to $7 \%$. Although the percentage of people who participated in part-time activities increased from $51 \%$ before the COVID-19 outbreak to $61 \%$ thereafter, the percentage of people who participated in full-time activities decreased from $32 \%$ to $10 \%$.

\section{Discussion}

The aim of this study was to provide an insight into the impact of quarantine and social distance on participation in activities of daily living and social interaction, based on data extracted from the responses of 461 people in Iran. In fact, the preliminary results of 461 participants showed that restrictive measures during the outbreak of COVID-19 have negative effects on the areas of the home integration, community integration, and productive and purposeful activities. The total score in the social participation questionnaire of the participants in the study has decreased by $47 \%$ compared to "before" the COVID-19 outbreak and restrictions. During similar epidemics (SARS prevalence between 2002 and 2004), previous research has shown several negative effects of quarantine measures on social participation that have been associated with reduced individual well-being \{Hawryluck, 2004 \#247\} \{Reynolds, 2008 \#248\}. These negative cases have also been reported in a recent series of COVID-19 reports, highlighting the fact that people in quarantine report more symptoms of mental distress. In addition, some of these symptoms appear to persist long after the end of quarantine\{Lima, 2020 \#249\}. With previous negative results from the COVID-19 pandemic in the field of social participation, the present findings, supported by previous reports, highlight the risk of socio-psychological stress in the period of quarantine and social distancing.

In particular, the decrease in the total score recorded in the Social Participation Questionnaire in all three areas of integration at home, integration in the community and integration in productive and purposeful activities compared to before the outbreak of COVID-19, means that participants after the outbreak of COVID-19 They were rarely involved in social activities and were therefore at greater risk for social isolation. This can be explained by social constraints, reduced engagement, quarantine, and distancing measures taken by government agencies to curb the spread of the virus \{Pancani, 2020 \#250\}. The findings of this study show that the decrease in the total score of social participation was mainly due to the decrease in social participation through recreational activities (71\% decrease). Continuous and daily leaving the house also shows the second-largest decrease ( $54 \%$ decrease). The widespread social isolation imposed on society by COVID-19 is detrimental to mental health. Indeed, a study of 1,006 quarantined Italians following the outbreak of COVID-19 found that quarantine increased depression, social isolation, and feelings of helplessness among individuals \{Pancani, 2020 \#250\}. In addition, people who stopped and quarantined for 1 month in China reported poor mental health and distress after 1 month \{Zhang, 2020 \#251\}.

COVID-19 has a profound effect on all aspects of society, including mental and physical health. Although concerns and ambiguities about epidemics are common, some of them cause unwanted disturbances in social and occupational functions \{Lima, 2020 \#249\}. In addition to the damage that the disease does to 
its sufferers, the fear of being infected, the loss of loved ones, the loss of a job, the loss of educational opportunities, recreation, freedom, and support, have profound psychological effects. Not only getting it but also the fear of getting it has led to a lack of access to resources that can improve people's resistance to this pandemic. The direct and indirect psychological and social effects of COVID-19 are widespread and can affect mental health \{Rajkumar, 2020 \#252\}.

A general population study conducted in this study shows the broad effects of this disease on social interactions and its consequences on lifestyle and social participation. Social participation is a tool for empowerment through which individuals learn to take responsibility for their own health problems and work to develop their communities \{Hyyppä, 2003 \#39\}\{Myroniuk, 2015 \#142\}. One of the effective factors in social growth and achieving optimal health is presence in social fields and active participation in society. People with high social participation have fewer physical and mental problems. There is a direct relationship between people's social participation and health-related quality of life. Also, social participation and social resources are strong presuppositions of health \{Lindström, $2001 \# 147\}\{$ Sirven, $2008 \# 146\}$.

The direct and indirect psychological and social effects of COVID-19 are widespread and can affect mental health. A general study of the population, conducted in this study, showed the widespread effects of the disease on social integration and its consequences on lifestyle and social participation. Social participation is a means of empowerment through which people learn to take responsibility for solving their health and wellness problems and strive to develop their communities\{Hyyppä, $2003 \# 141\}$ \{Myroniuk, $2015 \# 142\}$. One of the effective factors in social development and achieving optimal health is being in social fields and active social participation. People with high social participation had fewer physical and mental problems. There is a direct relationship between people's social participation and the life-quality associated with health. Social participation and social sources are strong predicting of health $(36,37)$. People with higher social participation have more ability and skill in managing their own and other people's emotions while facing problems and issues of occupational and life environment, and therefore face hardships, problems in daily life, and psychological tensions $(38,39)$. As a result, they are more likely to respond to adversity, daily life difficulties, and psychological problems and pressures, which in turn increase their resistance to mental disorders and their symptoms, and on the other hand increasing their success, satisfaction, and optimism, and thus increasing their happiness and health (37, $39,40)$.

People with higher social participation, due to awareness of their emotions and feelings, strong and healthy management, control and monitoring, stronger social networks, empathy, social skills, and greater social associations, can better resist various sources of permanent job stress, family, or social communication problems $(38,41)$. They can effectively resolve issues and problems. Therefore, these people can better communicate with their peers compared to people with lower levels of social participation. Besides, better manage their responsibilities, perform better and have an effective, fresh, and healthier presence in the workplace and other areas of their lives by spreading and gaining positive emotions about themselves $(38,41,42)$. Because mental fatigue and mental pain are the sources of many 
physical diseases, they will mutually affect a person's mental health and well-being. A person with mental and physical problems will be fragile in the face of environmental and occupational stress $(38,41,42)$. Long-time stressful stimuli result in the occurrence of depression, the first manifestation of which is extremely emotional and psychological fatigue, and lead to a decrease in public health and community productivity.

People who are more socially involved have more mental abilities to understand the situation temporarily and to respond to the pressures and tensions of the internal and external environment. Such capabilities usually empower the people for resistance against the symptoms of anxiety, stress, mental disorder, severe depression, stress, and social functioning $(39,40)$.

Fear of infecting by the disease associates with increased anxiety, depression, stress, and other negative emotions, and concerns about the practical consequences of the epidemic. It has a profound effect on the mental health of family members. Further, the disease affects psychological processes such as cognition, emotions, and behavior, as well as lifestyle and social communication, which ultimately affects mental health.

One of the social consequences of this disease is widespread anxiety disorders and depression. These include suicide and self-injury, alcohol and drug abuse, gambling, child abuse, and psychosocial disorders (such as interrupting social communication, being caught on the Internet, cyberspace addiction, feeling of stress, unemployment, homelessness, and losing social relationships). The consequences of the COVID-19 epidemic are likely exacerbated by isolation and social loneliness. Isolation and social disintegration are distinct problems and may show different risk pathways.

These data are critical in determining the causal mechanisms associated with poor mental health, including loneliness. In the face of the consequences of this disease, the available social and personal resources (e.g., meeting family and relatives), are among the resilience associated factors to resolve mental health problems in certain stressful situations, while the disease has attacked the resilience sources and destroyed them.

\section{Conclusions}

These findings show the impact of COVID-19 on various aspects of social life. These destructive effects disrupt the lives and health of individuals and their active participation in the areas of activity at home, social activities and productive activities. Among these, disruption of socially related activities has been most affected by the outbreak of COVID-19. In general, the outbreak of Covid-19 has affected all areas related to daily life activities. Social participation through contact with family and friends is reduced due to restrictions.

\section{Declarations}

Ethics approval and consent to participate:

Page $11 / 18$ 
This study was approved by the Ethic Committee of the University of Social Welfare and Rehabilitation Sciences, Tehran, Iran (IR.USWR.REC.1399.228).

\section{Consent for publication:}

Not applicable

\section{Availability of data and materials:}

The datasets used and/or analyzed during the current study are available (in Persian) from the corresponding author on reasonable

\section{Competing interests:}

"The authors declare that they have no competing interests"

\section{Funding:}

The university of Social welfare and Rehabilitation Sciences in the ethical approving the study

\section{Authors' contributions:}

EM: conducting survey, data collection, $\mathrm{MV}$ : analyzing data, $\mathrm{HH}$ : designing the study, supervising and monitoring the process, writing, correcting and submitting the manuscript. All authors read and approved the final manuscript

\section{Acknowledgements}

We acknowledge all participants, all the therapists, and colleagues who help us in delivering information and forms through different media to the participants.

\section{References}

1. Del Bono E, Sala E, Hancock R, Gunnell C, Parisi L. Gender, older people and social exclusion: A gendered review and secondary analysis of the data. ISER Working Paper Series; 2007.

2. Zimmerman S, Scott AC, Park NS, Hall SA, Wetherby MM, Gruber-Baldini AL, et al. Social engagement and its relationship to service provision in residential care and assisted living. 2003;27(1):6-18.

3. Zunzunegui M-V, Koné A, Johri M, Béland F, Wolfson C, Bergman HJSs, et al. Social networks and self-rated health in two French-speaking Canadian community dwelling populations over 65 . 2004;58(10):2069-81.

4. Berkman LF, Glass T, Brissette I, Seeman TEJSs, medicine. From social integration to health: Durkheim in the new millennium. 2000;51(6):843-57. 
5. Cicognani E, Pirini C, Keyes C, Joshanloo M, Rostami R, Nosratabadi MJSIR. Social participation, sense of community and social well being: A study on American, Italian and Iranian university students. 2008;89(1):97-112.

6. Utz RL, Carr D, Nesse R, Wortman CBJTG. The effect of widowhood on older adults' social participation: An evaluation of activity, disengagement, and continuity theories. 2002;42(4):522-33.

7. Prilleltensky I, Nelson G, Peirson LJJoC, Psychology AS. The role of power and control in children's lives: An ecological analysis of pathways toward wellness, resilience and problems. 2001;11(2):14358.

8. Smetana JG, Campione-Barr N, Metzger AJARP. Adolescent development in interpersonal and societal contexts. 2006;57:255-84.

9. Huber M, Knottnerus JA, Green L, van der Horst H, Jadad AR, Kromhout D, et al. How should we define health? 2011;343.

10. Organization WH. Active ageing: A policy framework. World Health Organization; 2002.

11. Chipuer HM, Bramston P, Pretty GJSir. Determinants of subjective quality of life among rural adolescents: A developmental perspective. 2003;61(1):79-95.

12. Litwin $\mathrm{H}$, Shiovitz-Ezra SJA, society. The association between activity and wellbeing in later life: what really matters? 2006;26:225.

13. Singh J, Singh JJERJoSS, Humanities. COVID-19 and its impact on society. 2020;2.

14. https://www.worldometers.info/coronavirus/ 2021 [Available from: https://www.worldometers.info/coronavirus/.

15. Drazen JM, Kanapathipillai R, Campion EW, Rubin EJ, Hammer SM, Morrissey S, et al. Ebola and quarantine. Mass Medical Soc; 2014.

16. Sohrabi C, Alsafi Z, O'Neill N, Khan M, Kerwan A, Al-Jabir A, et al. World Health Organization declares global emergency: A review of the 2019 novel coronavirus (COVID-19). 2020;76:71-6.

17. Nussbaumer-Streit B, Mayr V, Dobrescu Al, Chapman A, Persad E, Klerings I, et al. Quarantine alone or in combination with other public health measures to control COVID-19: a rapid review. 2020(9).

18. Wilder-Smith A, Freedman DOJJotm. Isolation, quarantine, social distancing and community containment: pivotal role for old-style public health measures in the novel coronavirus (2019-nCoV) outbreak. 2020;27(2):taaa020.

19. DiGiovanni C, Conley J, Chiu D, Zaborski JJB, bioterrorism: biodefense strategy $p$, science. Factors influencing compliance with quarantine in Toronto during the 2003 SARS outbreak. 2004;2(4):26572.

20. Rosenberger LH, Riccio LM, Campbell KT, Politano AD, Sawyer RGJSi. Quarantine, isolation, and cohorting: From cholera to Klebsiella. 2012;13(2):69-73.

21. Sofo A, Sofo AJHE. Converting home spaces into food gardens at the time of Covid-19 quarantine: All the benefits of plants in this difficult and unprecedented period. 2020;48(2):131-9. 
22. Ammar A, Brach M, Trabelsi K, Chtourou H, Boukhris O, Masmoudi L, et al. Effects of COVID-19 home confinement on eating behaviour and physical activity: results of the ECLB-COVID19 international online survey. 2020;12(6):1583.

23. Ammar A, Trabelsi K, Brach M, Chtourou H, Boukhris O, Masmoudi L, et al. Effects of home confinement on mental health and lifestyle behaviours during the COVID-19 outbreak: Insight from the “ECLB-COVID19” multi countries survey. 2020.

24. Ammar A, Mueller P, Trabelsi K, Chtourou H, Boukhris $O$, Masmoudi L, et al. Emotional consequences of COVID-19 home confinement: The ECLB-COVID19 multicenter study. 2020.

25. Brooks SK, Webster RK, Smith LE, Woodland L, Wessely S, Greenberg N, et al. The psychological impact of quarantine and how to reduce it: rapid review of the evidence. 2020;395(10227):912-20.

26. Qiu J, Shen B, Zhao M, Wang Z, Xie B, Xu YJGp. A nationwide survey of psychological distress among Chinese people in the COVID-19 epidemic: implications and policy recommendations. 2020;33(2).

27. Wang C, Pan R, Wan X, Tan Y, Xu L, Ho CS, et al. Immediate psychological responses and associated factors during the initial stage of the 2019 coronavirus disease (COVID-19) epidemic among the general population in China. 2020;17(5):1729.

28. Donthu N, Gustafsson A. Effects of COVID-19 on business and research. Journal of business research. 2020;117:284.

29. Chakraborty I, Maity PJSotTE. COVID-19 outbreak: Migration, effects on society, global environment and prevention. 2020;728:138882.

30. Bostan S, Erdem R, Öztürk YE, Kılıç T, Yılmaz AJEJoGM. The Effect of COVID-19 Pandemic on the Turkish Society. 2020;17(6).

31. Torales J, O’Higgins M, Castaldelli-Maia JM, Ventriglio AJIJoSP. The outbreak of COVID-19 coronavirus and its impact on global mental health. 2020;66(4):317-20.

32. Mahase E. Covid-19: Mental health consequences of pandemic need urgent research, paper advises. British Medical Journal Publishing Group; 2020.

33. Willer B, Ottenbacher KJ, Coad MLJAjopm, rehabilitation. The community integration questionnaire. A comparative examination. 1994;73(2):103-11.

34. Singh U, Sharma VJIJoH, Sciences R. Validity and reliability of community integration questionnaire in elderly. 2015;4(1):1-9.

35. Negahban H, Fattahizadeh P, Ghasemzadeh R, Salehi R, Majdinasab N, Mazaheri MJD, et al. The Persian version of Community Integration Questionnaire in persons with multiple sclerosis: translation, reliability, validity, and factor analysis. 2013;35(17):1453-9.

36. Sirven N, Debrand TJSs, medicine. Social participation and healthy ageing: an international comparison using SHARE data. 2008;67(12):2017-26.

37. Lindström M, Hanson BS, Östergren P-OJSs, medicine. Socioeconomic differences in leisure-time physical activity: the role of social participation and social capital in shaping health related 
behaviour. 2001;52(3):441-51.

38. MohammadiShahbolaghi F, SetareForuzan A, Hemmati S, Karimlu MJSWQ. Associated Factors with Community Participation in Health. 2013;13(48):47-72.

39. Rodriguez MI. Social participation and health promotion in El Salvador (1970-2014). Sage Publications Sage UK: London, England; 2014.

40. Shoja M, Nabavi S, Kassani AJJoNKUoMS. Factor analysis of social capital and its relations with mental health of older people in 9 districts of Tehran. 2012;3(5):81-90.

41. Alizadeh S, Mohseni M, Khanjani N, Momenabadi VJJoHPM. Correlation between social participation of women and their quality of life in Kerman. 2014;3(2):34-42.

42. Deck R, Walther AL, Staupendahl A, A. K. limitations of social participation in general populationnormative data of the IMET based on a population-based survey in northern Germany. Die Rehabilitation. 2015 54((6)):402-8.

\section{Figures}

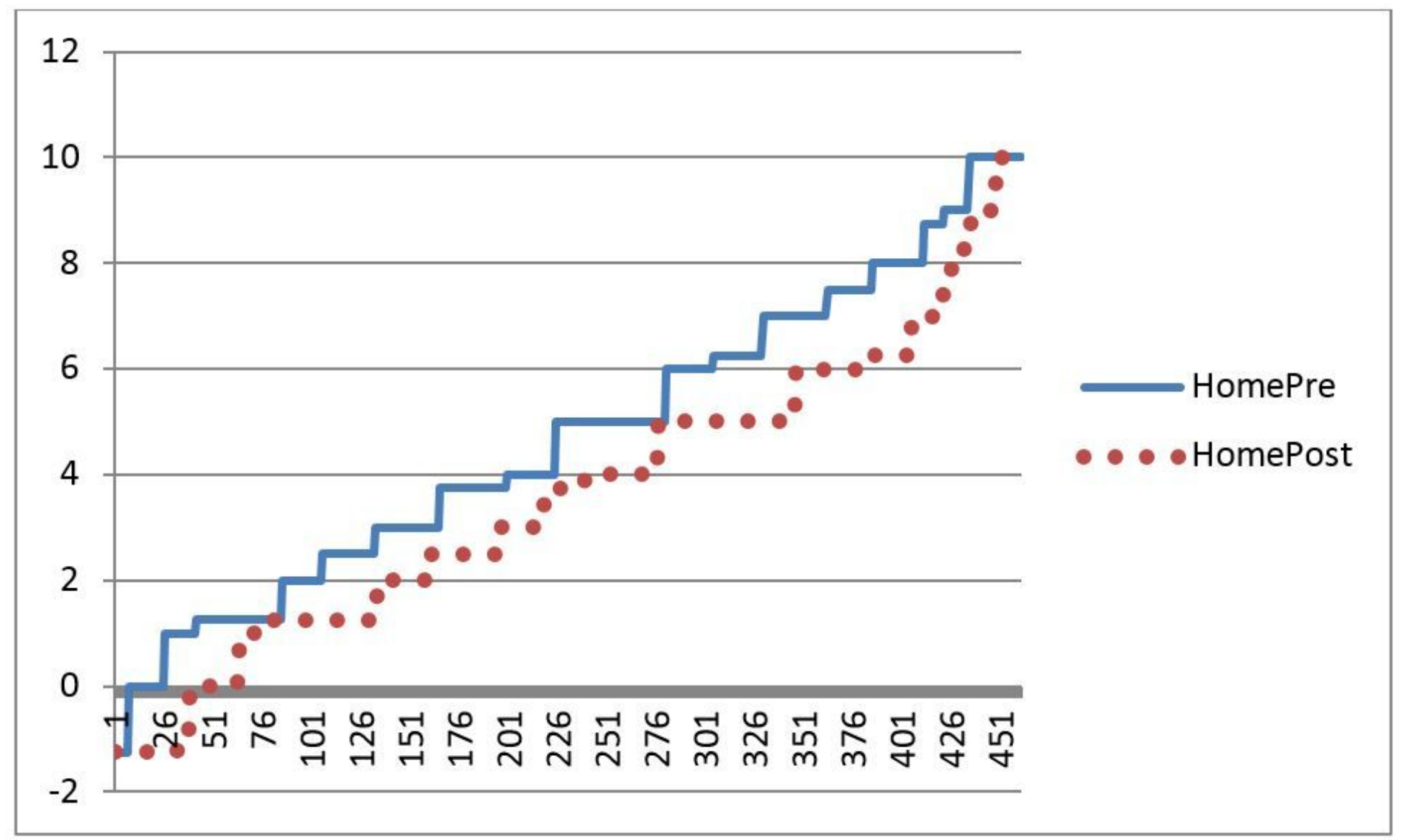

\section{Figure 1}

The trend of "home integration" activities before (line) and after (dotted line) COVID-19 in Iranian people. After COVID-19 the home integration scores decreased significantly in the participants. 


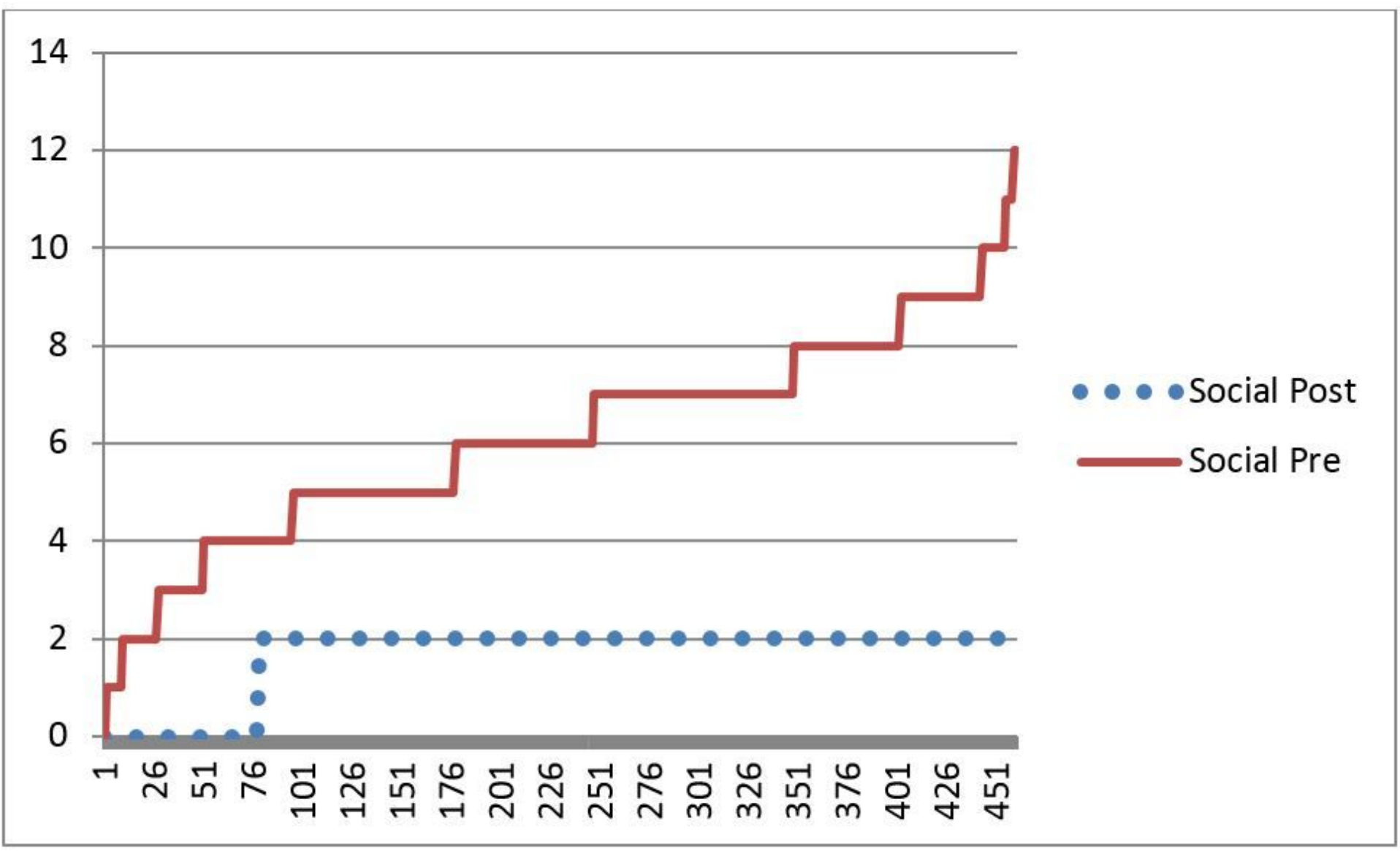

Figure 2

The trend of "social integration" activities before (line) and after (dotted line) COVID-19 in Iranian people. The people' score in social activities decreased significantly after the COVID-19 pandemic in the studied subjects. 


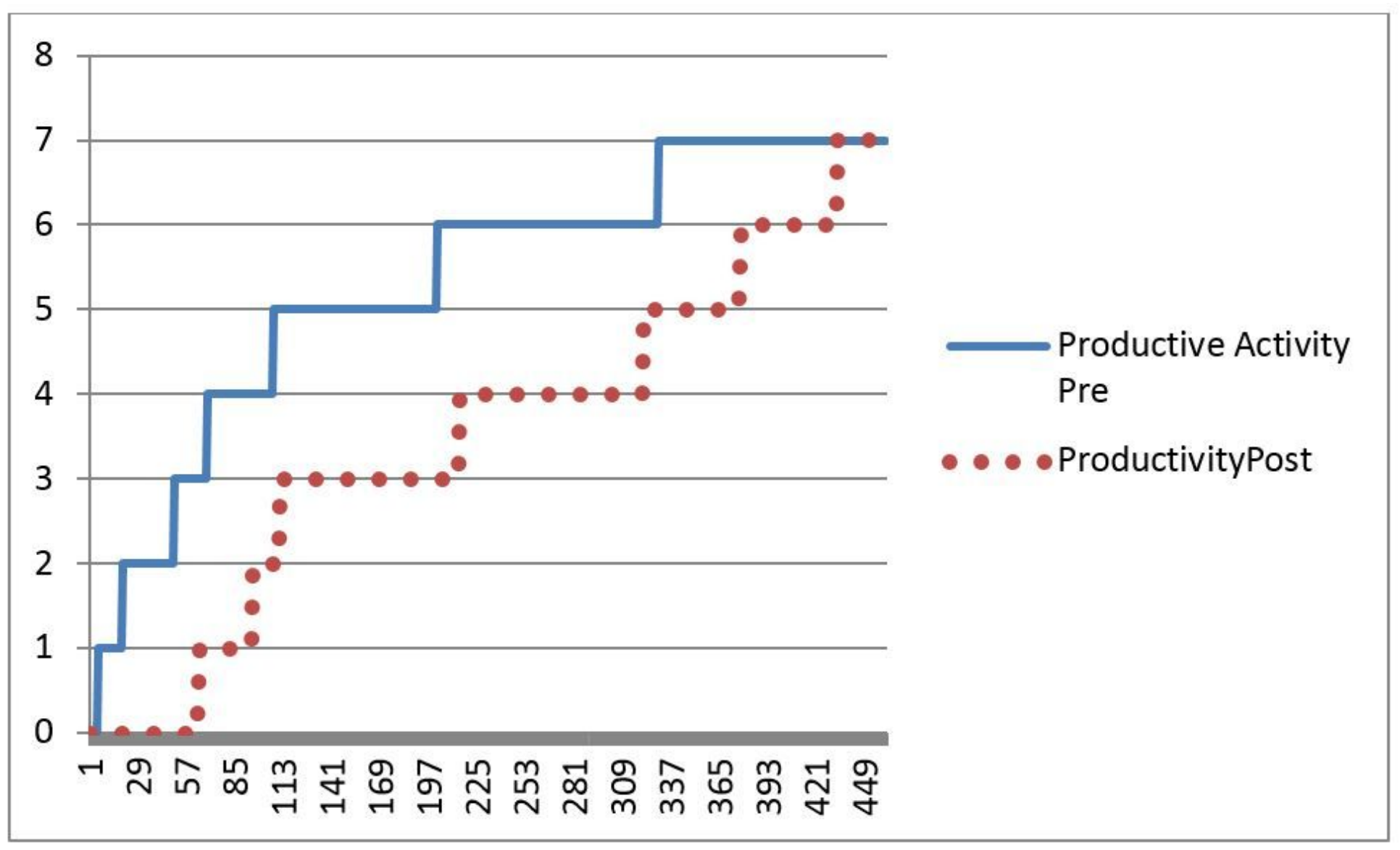

Figure 3

The trend of "integration into productive activities" before (line) and after (dotted line) COVID-19 in Iranian people. The diagram illustrates a significant decrease in productive activities after COVID-19 Pandemic. 


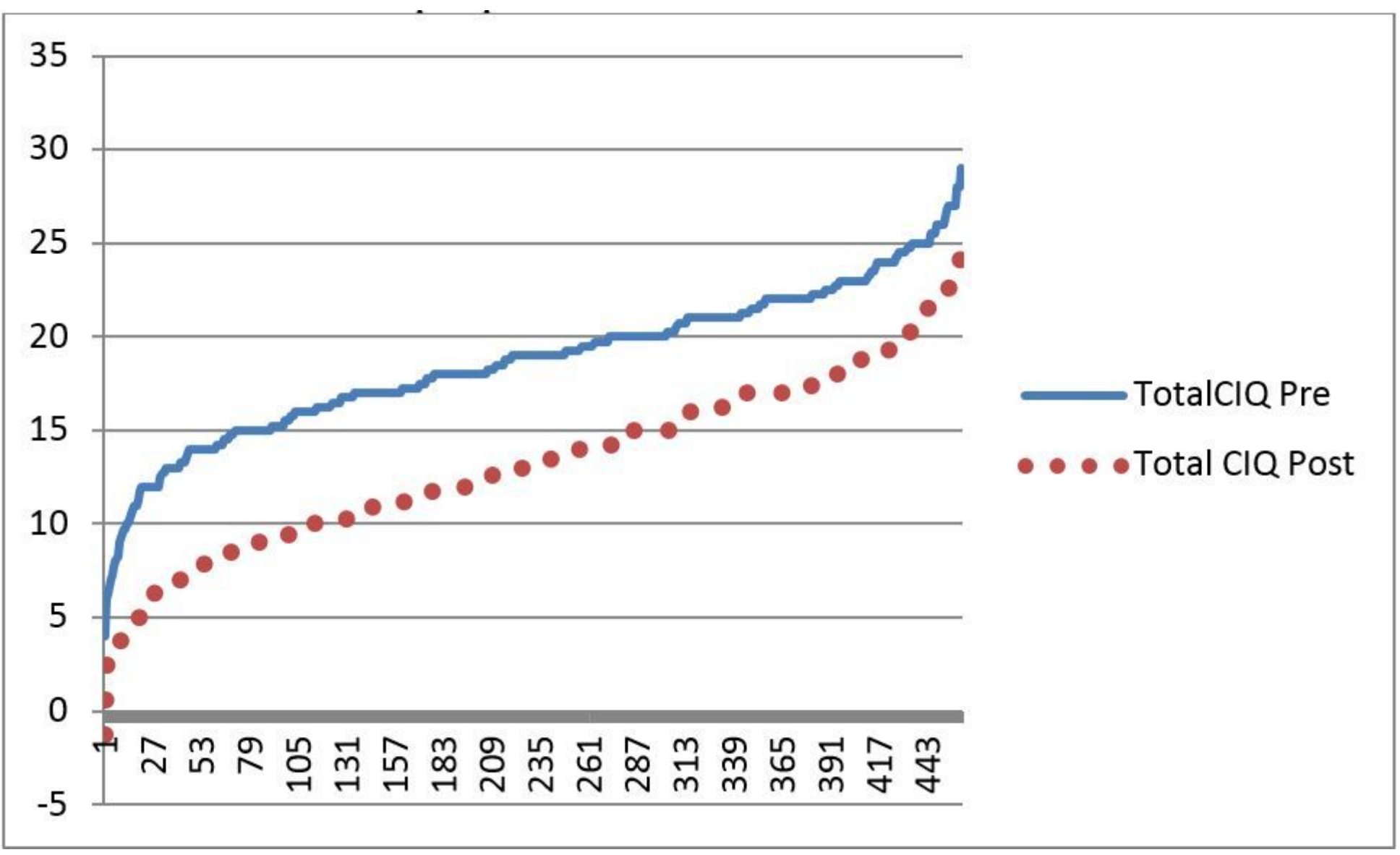

Figure 4

The trend of community integration (total CIQ) before (line) and after (dotted line) COVID-19 in Iranian people. 